\title{
PYRIDINE COMPOUNDS INCREASE TRAP CAPTURE OF FRANKLINIELLA OCCIDENTALIS (PERGANDE) IN A COVERED CROP
}

\author{
M.M. DAVIDSON, R.C. BUTLER, S. WINKLER ${ }^{1}$ and D.A.J. TEULON \\ Crop \& Food Research, Private Bag 4704, Christchurch, New Zealand \\ ${ }^{1}$ Current address: School of Biological Sciences, University of Auckland, \\ Private Bag 92019, Auckland, New Zealand
}

Corresponding author: davidsonm@crop.cri.nz

\begin{abstract}
The effect of pyridine compounds on the capture of thrips was examined in an Auckland, New Zealand, capsicum greenhouse in 2004. Yellow sticky traps were positioned just above the crop canopy in a rectangular array with 6 traps per compound and 6 control traps, 20-24 m apart, and left for $24 \mathrm{~h}$. Most thrips found on traps were Frankliniella occidentalis (>99\%). Fourteen times more female F. occidentalis were captured on traps with methyl isonicotinate or ethyl isonicotinate than on controls. Sticky traps treated with methyl 4-pyridyl ketone also caught more female $F$. occidentalis than controls $(4.5 \times)$. Sticky traps with methyl isonicotinate caught more male F. occidentalis (up to 5.2x) than controls. Ethyl-2-chloropyridine-4-carboxylate and ethyl nicotinate did not increase trap catches of either sex. The results demonstrated that selected pyridine compounds have the potential to improve trap capture of $F$. occidentalis in a covered crop.
\end{abstract}

Keywords: odours, visual cues, pyridine derivatives, Frankliniella occidentalis.

\section{INTRODUCTION}

In New Zealand, and elsewhere, Frankliniella occidentalis (Pergande) is a key pest of covered crops (Martin \& Workman 1994; Lewis 1997). Frankliniella occidentalis can cause direct feeding damage and transmit viruses to plants (Lewis 1997). It is difficult to manage because of its small size, cryptic habits and resistance to some insecticides (Lewis 1997). Its response to visual cues has been exploited through the use of coloured sticky traps to monitor populations (Brødsgaard 1993). Frankliniella occidentalis also responds to odours, such as pheromones (alarm, sex and aggregation) (Teerling et al. 1993; de Kogel \& van Deventer 2003; Hamilton et al. 2005) and odours from host plants (Teulon et al. 1993; Koschier et al. 2000). Coloured traps with host-plant odours have caught 1.3- 5.6× more F. occidentalis than traps without odour (Brødsgaard 1990; Frey et al. 1994; Teulon et al. 1993). A commercially available aggregation pheromone has been shown to increase capture of $F$. occidentalis on blue sticky traps by up to $3 \times$ compared to traps without the pheromone (Gomez et al. 2006). Such odours could be used to improve monitoring, mass trapping, lure and infect, attract and kill, and push-pull strategies (Agelopoulos et al. 1999).

In New Zealand, Thrips obscuratus (Crawford) and Thrips tabaci Lindeman have been shown to respond to an ethyl nicotinate and several related pyridine compounds (Penman et al. 1982; D.A.J. Teulon, unpubl. data). Field trials using water traps with ethyl nicotinate caught up to 100x more Thrips obscuratus (Crawford) than traps without the odour (Penman et al. 1982). Subsequent water trap trials showed that traps with a range of pyridine compounds caught between 5 and $62 \times$ more Thrips tabaci Lindeman than controls (provisional patent, Davidson et al. 2005; D.A.J. Teulon, unpubl. data). 
The response of $F$. occidentalis toward 13 of these pyridine compounds was initially evaluated in the laboratory using a Y-tube olfactometer (Davidson et al. 2005). The Y-tube allows a large number of compounds to be screened over a relatively short space of time, unlike in a greenhouse where the limited area available allows for very few compounds to be tested at a given time. Several compounds resulted in significantly more thrips choosing the odour arm of the Y-tube for a wide range of concentrations $\left(10^{-6}\right.$ to $1 \mu \mathrm{l})$, including ethyl isonicotinate, methyl isonicotinate, methyl-4-pyridyl ketone and ethyl-2-chloropyridine carboxylate (Davidson et al. 2005).

The aim of this study was to evaluate the effect of some pyridine compounds, ethyl nicotinate, ethyl isonicotinate, methyl isonicotinate, methyl-4-pyridyl ketone and ethyl-2-chloropyridine carboxylate, on $F$. occidentalis trap capture in a commercial greenhouse.

\section{METHODS}

Experimental work was carried out in a commercial greenhouse in Auckland, New Zealand, in 2004. The 2 ha Dutch-style greenhouse was constructed of glass and used to grow capsicum (Capsicum annuum cvs Special, Fiesta, Boogie and Stirit).

\section{Chemicals}

The compounds tested were ethyl nicotinate, ethyl isonicotinate, methyl isonicotinate, methyl 4-pyridyl ketone and ethyl-2-chloropyridine-4-carboxylate. All compounds were purchased from Sigma-Aldrich, except ethyl-2-chloropyridine-4-carboxylate, which was synthesised using the method described in Davidson et al. (2005).

\section{Experimental design}

A total of 12 paired sticky traps (6 traps with a compound, 6 control traps) were positioned in a rectangular array in the greenhouse. Sticky traps were placed 20-24 m apart within a row and $24 \mathrm{~m}$ apart between rows.

The compounds ethyl nicotinate, ethyl isonicotinate, methyl isonicotinate and methyl 4-pyridyl ketone were tested on two separate occasions, while ethyl-2-chloropridine4-carboxylate was tested once. Each compound was tested separately over a $24 \mathrm{~h}$ period against control traps for selected dates between 12 July and 3 August 2004 (Table 1). Yellow sticky traps $(24.4 \mathrm{~cm}$ long $\times 20 \mathrm{~cm}$ wide, Veg-Gro Supplies Ltd, Auckland) were treated with a compound or water (control) in the laboratory using a $30 \mathrm{ml}$ spray mist dripulator (Arthur Holmes, Wellington) held $10 \mathrm{~cm}$ away from the sticky trap. Four sprays were applied to each side, coating the sticky trap in approximately $1 \mathrm{ml}$ of water (control) or odour. Sticky traps sprayed with the same compound or water were separated using black metal foldback clips (19 mm, Celco) and suspended within a cardboard box $(29.5 \times 22.3 \times 30.2 \mathrm{~cm})$, which was in turn sealed within a plastic bag for transport to the greenhouse. Traps were suspended in the greenhouse just above the crop canopy (approximately $1.5 \mathrm{~m}$ above ground) within $3 \mathrm{~h}$ of being sprayed with an odour or water. After $24 \mathrm{~h}$ the traps were collected and wrapped separately in plastic wrap for transport to the laboratory.

The total number of thrips from each trap was recorded. Thrips were removed from the sticky traps using De-Solv-it ${ }^{\circledR}$ and all recovered thrips were mounted on to slides. All intact terebrantian thrips were identified under 100x magnification according to Mound \& Walker (1982), with allowance for several additions/corrections in thrips species in New Zealand since that time (L. Mound, pers. comm.).

\section{Statistical analysis}

Data from each date were analysed using a standard Poisson generalised linear model (with the standard logarithmic link) (McCullagh \& Nelder 1989). Results are presented as back-transformed mean counts and associated $95 \%$ confidence limits. The ratio for the mean of each treatment to the control mean was also obtained, and the $t$-statistics were calculated for these ratios on the $\log$-scale $(t=\log ($ ratio $) / \operatorname{se}(\log ($ ratio $))$; t-values $>2$ are significant at, at least, the 5\% level. All analyses were carried out using Genstat (9th edition VSN International, Hemel Hempsted). 


\section{RESULTS AND DISCUSSION}

The majority of thrips caught on yellow sticky traps over the trapping period were male and female $F$. occidentalis $(99.55 \%)$. Other thrips species caught on the traps included T. obscuratus $(0.4 \%)$ and T. australis Bagnall $(0.05 \%)$. The numbers of male and female F. occidentalis are presented separately to evaluate the effect of odour on the different sexes (Table 1). Generally more male $F$. occidentalis (mean=9.5) were caught on control traps than females (mean=2.5) throughout the experiment. Relatively high numbers of thrips were caught on sticky traps during the July experiments. Insecticides were applied for thrips control by the grower on 18 and 22 July, but thrips numbers still remained relatively high on 19 and 20 July. Numbers of male and female F. occidentalis thrips were much lower in August so comparisons at this time are based on very low numbers.

In July, generally more female $F$. occidentalis were caught on traps treated with methyl isonicotinate, ethyl isonicotinate or methyl 4-pyridyl ketone than the control traps (Table 1). Also, more male F. occidentalis were caught on methyl isonicotinate traps than on control traps (Table 1). A similar number of male and female $F$. occidentalis were caught on traps treated with ethyl-2-chloropyridine-4-carboxylate or ethyl nicotinate and control traps.

Traps treated with methyl isonicotinate caught 9.4 and $14 \times$ more female, and 2.2 and $5.2 \times$ more male $F$. occidentalis than control traps on 13 and 19 July respectively (Table 1). Additionally, $14 \times$ more female F. occidentalis (but only $1.8 \times$ more males) were caught on traps with ethyl isonicotinate compared to control traps on 12 July. These results compare favourably with other reports of improved trapping for $F$. occidentalis with odours. Teulon et al. (1993) reported 1.8-5.6× more female and 0.9-2.2 $\times$ more male F. occidentalis on sticky traps treated with a plant-derived odour than on traps without the odour in commercial greenhouses. By comparison, an aggregation pheromone increased sticky trap capture of female and male $F$. occidentalis by $1.9 \times$ and $1.5 \times$ respectively in a commercial greenhouse (Hamilton et al. 2005). While Gomez et al. (2006) recorded an increase in F. occidentalis of up to $3 \times$ on traps with the aggregation pheromone compared to controls, they did not distinguish between male and female F. occidentalis, so their results cannot be compared to those from the present study.

The relatively low response of $F$. occidentalis males to these chemicals is interesting, as both males and females of Thrips obscuratus were similarly responsive to traps with ethyl isonicotinate in outdoor field studies (D.A.J. Teulon, unpubl. data). However, the increased capture of female thrips, compared to male thrips, is likely to bring about a greater reduction in overall thrips population numbers as female thrips can lay eggs without mating. Additional research on the response to these chemicals from a range of thrips species would be valuable.

Recent studies have shown that a range of pyridine compounds, including those tested here, significantly increase the capture of T. tabaci in water traps in outdoor field trials (D.A.J. Teulon, unpubl. data). Additionally, F. occidentalis has been found to respond positively to these chemicals in Y-tube olfactometer bioassays (Davidson et al. 2005).

The results presented here indicate that some pyridine compounds, especially ethyl and methyl isonicotinate, significantly increase trap capture of $F$. occidentalis females (and sometimes males) under greenhouse conditions. Unfortunately, the experimental design, which had to take into account the relatively small enclosed trapping area and the fact that closely spaced traps interfere with each other (Teulon et al. 2007), precluded direct comparison between the different compounds tested.

This paper provides the first published information on the efficacy of a new group of thrips chemical lures in greenhouses. The experiments presented here are somewhat limited in scope but provide the basis for examining the effect of intrinsic (e.g. sex, ovarian development, satiation and mating status) and extrinsic factors (e.g. temperature, light, relative humidity, and the suitability and developmental stage of host plant) on greenhouse-inhabiting thrips and the poorly understood behavioural mechanisms underlying thrips' response toward visual and olfactory stimuli. Furthermore, research comparing thrips trap capture with respect to the resident thrips population using a range 
TABLE 1: Mean numbers (95\% confidence limits) of male and female F. occidentalis on sticky traps, and the ratio (t-value, values $>2$ are significant at, at least, the $5 \%$ level) relative to the control. Insecticides were sprayed on 18 and 22 July, as indicated by the dotted lines.

\begin{tabular}{|c|c|c|c|c|}
\hline \multirow{2}{*}{ Treatment } & \multicolumn{2}{|c|}{ F. occidentalis 오 } & \multicolumn{2}{|c|}{ F. occidentalis $0^{\top}$} \\
\hline & Mean & Ratio & Mean & Ratio \\
\hline \multicolumn{5}{|l|}{12 July } \\
\hline Control & $0.2(0.0,10.6)$ & - & $10.0(6.0,16.7)$ & - \\
\hline Ethyl isonicotinate & $2.3(0.8,7.2)$ & $14.0(1.3)$ & $17.7(12.0,26.0)$ & $1.8(1.9)$ \\
\hline \multicolumn{5}{|l|}{13 July } \\
\hline Control & $0.8(0.1,9.6)$ & - & $9.5(6.2,14.6)$ & - \\
\hline Methyl isonicotinate & $7.8(3.5,17.4)$ & $9.4(1.8)$ & $21.3(16.0,28.4)$ & $2.2(3.3)$ \\
\hline \multicolumn{5}{|l|}{14 July } \\
\hline Control & $3.5(0.7,18.3)$ & - & $20.7(11.2,38.2)$ & - \\
\hline $\begin{array}{l}\text { Ethyl-2-chloropyridine- } \\
\text { 4-carboxylate }\end{array}$ & $1.8(0.2,18.2)$ & $0.5(0.5)$ & $31.2(18.9,51.4)$ & $1.5(1.1)$ \\
\hline \multicolumn{5}{|l|}{15 July } \\
\hline Control & $5.0(0.9,27.6)$ & - & $23.0(12.6,41.9)$ & - \\
\hline $\begin{array}{l}\text { Methyl 4-pyridyl } \\
\text { ketone }\end{array}$ & $22.5(10.0,50.4)$ & $4.5(1.7)$ & $33.7(20.5,55.2)$ & $1.5(1.0)$ \\
\hline \multicolumn{5}{|l|}{16 July } \\
\hline Control & $3.2(0.2,42.9)$ & - & $18.2(9.0,36.6)$ & - \\
\hline Ethyl nicotinate & $5.2(0.7,40.5)$ & $1.6(0.3)$ & $23.3(12.6,43.3)$ & $1.3(0.6)$ \\
\hline \multicolumn{5}{|l|}{19 July } \\
\hline Control & $2.2(0.3,15.9)$ & - & $1.8(0.6,5.4)$ & - \\
\hline Methyl isonicotinate & $29.8(17.4,51.0)$ & $13.8(2.7)$ & $9.5(5.9,15.3)$ & $5.2(3.0)$ \\
\hline \multicolumn{5}{|l|}{20 July } \\
\hline Control & $7.0(3.7,13.4)$ & - & $1.8(0.7,4.6)$ & - \\
\hline Ethyl nicotinate & $10.0(5.8,17.2)$ & $1.4(0.9)$ & $4.0(2.2,7.4)$ & $2.2(1.5)$ \\
\hline \multicolumn{5}{|l|}{2 August } \\
\hline Control & $0.3(0.1,1.0)$ & - & $0.0\left(0.0,-^{1}\right)$ & - \\
\hline Ethyl isonicotinate & $0.0\left(0.0,-^{1}\right)$ & $0.0(0.2)$ & $1.2(0.6,2.2)$ & $-^{2}$ \\
\hline \multicolumn{5}{|l|}{3 August } \\
\hline Control & $0.2(0.0,1.2)$ & - & $0.3(0.1,2.1)$ & - \\
\hline Methyl 4-pyridyl ketone & $0.2(0.0,1.2)$ & $1.0(0.0)$ & $1.8(0.8,4.0)$ & $5.5(1.8)$ \\
\hline
\end{tabular}

${ }^{1}$ Upper confidence limit can not be estimated.

${ }^{2}$ Cannot calculate a ratio to zero.

of sampling methods (e.g. thrips counts in flowers and whole plant counts) and ambient environmental conditions (e.g. light, temperature and relative humidity) would be valuable for understanding how to optimise the use of these odours in thrips pest management.

\section{ACKNOWLEDGMENTS}

The authors thank Luke Marks for allowing the trials to be carried out in a NZ HOTHOUSE greenhouse. Thanks to Vanessa Green and Lesley Larsen for synthesising ethyl-2-chloropyridine-4-carboxylate. Thanks to Nadine Berry for helpful comments on the original manuscript. This work was funded by the New Zealand Foundation for Research, Science and Technology (C02X0202). 


\section{REFERENCES}

Agelopoulos N, Birkett MA, Hick AJ, Hooper AM, Pickett JA, Pow EM, Smart LE, Smiley DWM, Wadhams LJ, Woodcock CM 1999. Exploiting semiochemicals in insect control. Pesticide Science 55: 225-235.

Brødsgaard HF 1990. The effect of anisaldehyde as a scent attractant for Frankliniella occidentalis (Thysanoptera: Thripidae) and the response mechanism involved. SROP/WPRS Bulletin XIII: 36-38.

Brødsgaard HF 1993. Coloured sticky traps for thrips (Thysanoptera: Thripidae) monitoring on glasshouse cucumbers. IOBC/WPRS Bulletin 16(2): 19-22.

Davidson MM, Teulon DAJ, Perry NB 2005. Insect behaviour modifying compounds. Chemical Abstracts 2005:447660; Crop \& Food Research: Provisional Patent PCT International, WO2005046330, 2005.

de Kogel WJ, van Deventer P 2003. Intraspecific attraction in the western flower thrips, Frankliniella occidentalis; indications for a male sex pheromone. Entomologia Experimentalis et Applicata 107: 87-89.

Frey JE, Cortada RV, Helbling H 1994. The potential of flower odours for use in population monitoring of western flower thrips Frankliniella occidentalis Perg. (Thysanoptera: Thripidae). Biocontrol Science and Technology 4: 177-186.

Gómez M, Garcia F, GreatRex R, Lorca M, Serna A 2006 Preliminary field trials with the synthetic sexual aggregation pheromone of Frankliniella occidentalis on protected pepper and tomato crops in South-east Spain. IOBC/WPRS Bulletin 29: 153-158.

Hamilton JGC, Hall D, Kirk WDJ 2005. Identification of a male-produced aggregation pheromone in the Western flower thrips, Franliniella occidentalis. Journal of Chemical Ecology 31: 1369-1379.

Koschier EH, de Kogel WJ, Visser JH 2000. Assessing the attractiveness of volatile plant compounds to western flower thrips Frankliniella occidentalis. Journal of Chemical Ecology 26: 2643-2655.

Lewis T 1997. Thrips as crop pests. CAB International, Wallingford, Oxon, U.K. 740 pp.

Martin NA, Workman PJ 1994. Confirmation of pesticide-resistant strain of western flower thrips in New Zealand. Proceedings of the 47th New Zealand Plant Protection Conference: 144-148.

McCullagh P, Nelder JA 1989. Generalized Linear Models. 2nd ed. Chapman \& Hall, London.

Mound LA, Walker AK 1982. Terebrantia (Insecta: Thysanoptera). Fauna of New Zealand 1: 1-113.

Penman DR, Osborne GO, Worner SP, Chapman RB, McLaren GF 1982. Ethyl nicotinate: A chemical attractant for Thrips obscuratus (Thysanoptera: Thripidae) in stonefruit in New Zealand. Journal of Chemical Ecology 8: 1299-1303.

Teerling CR, Gillespie DR, Borden JH 1993. Utilization of western flower thrips alarm pheromone as a prey-finding kairomone by predators. Canadian Entomologist 125: 431-437.

Teulon DAJ, Penman DR, Ramakers PMJ 1993. Volatile chemicals for thrips (Thysanoptera: Thripidae) host-finding and applications for thrips pest management. Journal of Economic Entomology 86: 1405-1415.

Teulon DAJ, Butler RC, James DE, Davidson MM 2007. Odour baited traps influence thrips (Thysanoptera) capture in proximal unbaited traps in the field. Entomologia Experimentalis et Applicata (doi:10.1111/j.1570-7458.2007.00554.x). 